\title{
Comparison between Investigational IR and Crystallographic Data with Computational Chemistry Tools as Validation of the Methods
}

\author{
U. C. Abdul Jaleel, ${ }^{1}$ M. Rakhila, ${ }^{1}$ and Geetha Parameswaran ${ }^{2}$ \\ ${ }^{1}$ Cheminformatics division, Malabar Christian College, Calicut 673001, India \\ ${ }^{2}$ Department of Chemistry, University of Calicut, India
}

Correspondence should be addressed to U. C. Abdul Jaleel, jaleel.uc@gmail.com

Received 30 June 2009; Revised 12 December 2009; Accepted 14 March 2010

Academic Editor: Kimihiko Hirao

Copyright ( $) 2010$ U. C. Abdul Jaleel et al. This is an open access article distributed under the Creative Commons Attribution License, which permits unrestricted use, distribution, and reproduction in any medium, provided the original work is properly cited.

Computational tools, specifically molecular mechanical force field (MM+) and semiempirical (PM3) and density functional methods (DFT) are applied to sets of schiff bases and their complexes. The results are compared with experimental data. It is also found that the simulated IR spectra are in consistence with the experimental data.

\section{Introduction}

Previously the theory of transition-metal chemistry has lagged behind the computational theory of organic chemistry because quantitative methods were more complicated [1]. In recent years computational coordination chemistry is passing the infancy and gaining its momentum. The molecular mechanics and quantum mechanical theories are predicting comparatively accurate results. A major place in the computational tools parameterization and substantiation is done by evaluating how well the experimental data are reproduced and comparing their correctness to the accuracy needed in the parameterization and substantiation of the particular method [2]. As a validation tool, our research group decided to compare the X-ray crystallographic data and experimental IR data with the molecular mechanics $(\mathrm{MM}+)$, semi empirical data(PM3), and density functional method (DFT) obtained by various molecular modeling softwares.

We selected certain schiff bases and complexes for which $X$ ray crystallographic and IR data were available in the literature. One of the selected series of complexes was that of schiff-base ligands containing salicylaldehyde and amino acids. The crystal and IR studies of this compound were published by Sreenivasulu et al. [3]. These model studies of the metal complexes had focused upon the binding mode of these ligands.

Sreenivasulu et al. had synthesized and characterized three Schiff-base ligands:

(1) $\{[(E)$-(2-hydroxyphenyl) methylidene $]$ amino $\}$ methanesulfonic acid which is abbreviated as Figure 1 structure of $\mathrm{H}_{2} \mathrm{Sams}$,

(2) 2 -\{[(E)-(2-hydroxyphenyl) methylidene $]$ amino $\}$ ethanesulfonic acid which is abbreviated as Figure 2 structure of $\mathrm{H}_{2} \mathrm{Sae}$,

(3) 2-[(2-hydroxybenzyl) amino] ethanesulfonic acid which abbreviated as Figure 3 structure of $\mathrm{H}_{2} \mathrm{Sae}$

and their $\mathrm{Cu}$ complexes by some experimental methods. They gave observed wave numbers for the important infrared spectral bands of the ligands and their metal complexes by using IR spectroscopy. They have reported observed X ray crystallographic bond distances and bond angles.

X-ray crystal structures of complexes thus obtained demonstrated that the schiff-base ligand acts as a tridentate moiety, coordinating through the phenolato oxygen [4], imine nitrogen, and carboxylate oxygen [5-8]. Our group is interested in this series of schiff-base ligands, specifically $\mathrm{N}$-(2-hydroxybenzyl) amino acids, because the flexibility of 


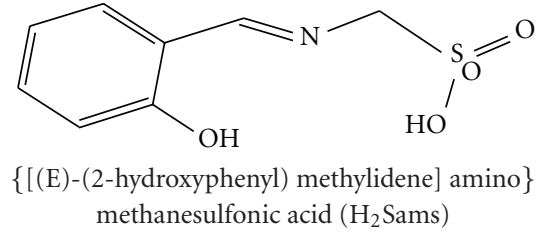

Figure 1

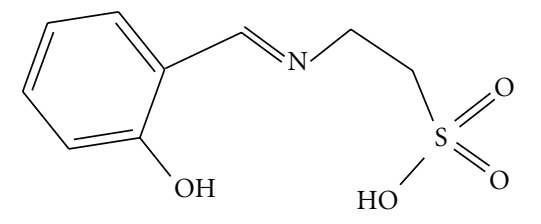

2-\{[(E)-(2-hydroxyphenyl) methylidene $]$ amino $\}$ ethanesulfonic acid $\left(\mathrm{H}_{2}\right.$ Saes $)$

Figure 2

TABLE 1: Bond distances of complex $\left[\mathrm{Cu}_{2}(\mathrm{Sams})_{2}\left(\mathrm{H}_{2} \mathrm{O}\right)_{2}\right]$ unit in $\AA$.

\begin{tabular}{lcccc}
\hline & X-ray & MM+ & PM3 & DFT \\
\hline $\mathrm{Cu}(1)-\mathrm{O}(1)$ & 1.89 & 1.86 & 1.84 & 1.94 \\
$\mathrm{Cu}(1)-\mathrm{O}(5)$ & 1.93 & 2.01 & 1.94 & 1.96 \\
$\mathrm{Cu}(1)-\mathrm{N}(1)$ & 1.93 & 1.91 & 1.88 & 2.01 \\
$\mathrm{Cu}(1)-\mathrm{O}(2)$ & 2.01 & 1.89 & 1.84 & 1.92 \\
$\mathrm{Cu}(1)-\mathrm{O}(3) \mathrm{A}$ & 2.39 & 1.84 & 1.92 & 1.89 \\
$\mathrm{O}(3)-\mathrm{Cu}(1) \mathrm{A}$ & 2.39 & 1.84 & 1.84 & 1.93 \\
$\mathrm{~N}(1)-\mathrm{C}(7)$ & 1.29 & 1.32 & 1.31 & 1.20 \\
$\mathrm{~N}(1)-\mathrm{C}(8)$ & 1.45 & 1.50 & 1.45 & 1.51 \\
$\mathrm{Cu}(1)-\mathrm{Cu}(1) \mathrm{A}$ & 5.12 & 4.42 & 4.42 & 4.43 \\
\hline
\end{tabular}

this molecule for reduction can be followed by IR and X ray crystallography more specifically.

The structures of ligand and complex molecules were constructed by HyperChem 8.0 [9]. In order to find optimized conformations, we executed conformational search [10] by simulated annealing method which has been described in detail later.

We constructed the structure of ligand and complexes by using Hyperchem GUI $\mathrm{H}_{2} \mathrm{Sams}, \mathrm{H}_{2} \mathrm{Saes}$, and $\mathrm{H}_{2} \mathrm{Sae}$, and their complexes $\left[\mathrm{Cu}_{2}(\mathrm{Sams})_{2}\left(\mathrm{H}_{2} \mathrm{O}\right)_{2}\right],\left[\mathrm{Cu}_{2}(\mathrm{Saes})_{2}\right.$ $\left.\left(\mathrm{H}_{2} \mathrm{O}\right)_{2}\right] \cdot 2 \mathrm{H}_{2} \mathrm{O}$, and $\left[\mathrm{Cu}_{2}(\mathrm{Sae})_{2}\right] \cdot 2 \mathrm{H}_{2} \mathrm{O}$ are modeled and shown in Figures 7-9

\section{Materials and Methods}

The crystallographic model developed by Sreenivasulu et al. [3] is given in Figures 4, 5, and 6.

2.1. Molecular Mechanics Optimization Ligand and Complexes. All the molecular mechanics calculations were carried out on Pentium IV $2.46 \mathrm{GHz}$ with the $\mathrm{MM}+$ force

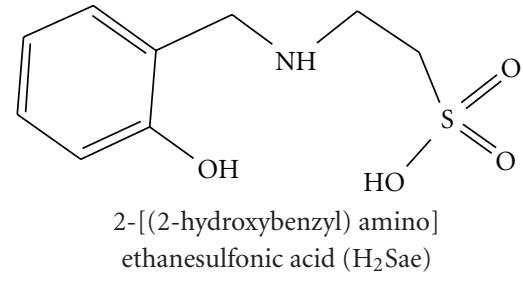

Figure 3

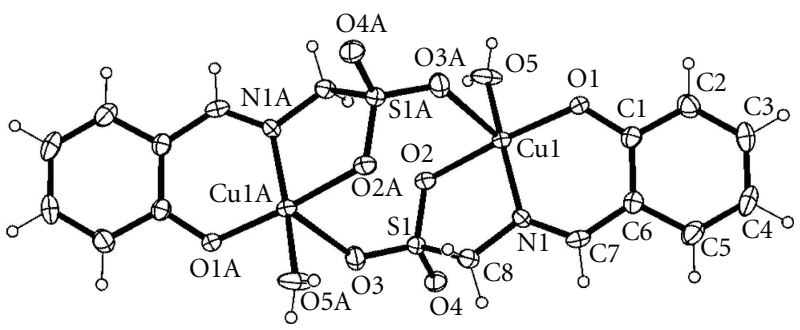

FIgure 4: Crystal structure of $\left[\mathrm{Cu}_{2}(\mathrm{Sams})_{2}\left(\mathrm{H}_{2} \mathrm{O}\right)_{2}\right]$ reprinted with permission.

TABLe 2: Bond angles of complex $\left[\mathrm{Cu}_{2}\left(\mathrm{Sams}_{2}\right)_{2}\left(\mathrm{H}_{2} \mathrm{O}\right)_{2}\right]$ in degrees.

\begin{tabular}{lcccc}
\hline & X-ray & MM+ & PM3 & DFT \\
\hline $\mathrm{S}(1)-\mathrm{O}(2)-\mathrm{Cu}(1)$ & 117.70 & 125.33 & 113.23 & 118.40 \\
$\mathrm{~S}(1)-\mathrm{O}(3)-\mathrm{Cu}(1) \mathrm{A}$ & 131.60 & 127.41 & 127.47 & 127.00 \\
$\mathrm{O}(1)-\mathrm{Cu}(1)-\mathrm{O}(5)$ & 91.36 & 94.96 & 94.08 & 91.08 \\
$\mathrm{O}(1)-\mathrm{Cu}(1)-\mathrm{N}(1)$ & 92.20 & 92.20 & 96.60 & 88.50 \\
$\mathrm{O}(5)-\mathrm{Cu}(1)-\mathrm{N}(1)$ & 165.60 & 119.10 & 109.97 & 121.52 \\
$\mathrm{O}(1)-\mathrm{Cu}(1)-\mathrm{O}(2)$ & 175.60 & 175.60 & 167.89 & 177.09 \\
$\mathrm{O}(1)-\mathrm{Cu}(1)-\mathrm{O}(3) \mathrm{A}$ & 96.82 & 85.47 & 86.26 & 93.40 \\
$\mathrm{O}(5)-\mathrm{Cu}(1)-\mathrm{O}(3) \mathrm{A}$ & 89.12 & 92.10 & 92.72 & 94.76 \\
$\mathrm{~N}(1)-\mathrm{Cu}(1)-\mathrm{O}(3) \mathrm{A}$ & 104.10 & 146.00 & 156.77 & 143.00 \\
\hline
\end{tabular}

field.The search for the lowest energy conformations was performed by Monte Carlo method. This method generated new conformations with randomly varied torsion angle. Monte Carlo search used the temperature $T=300 \mathrm{~K}$ to $400 \mathrm{~K}$. The molecule obtained was minimized by using Polak-Ribiere optimizer. Energy minimization was terminated when the gradient root mean square was below $0.01 \mathrm{k} \mathrm{cal} / \mathrm{mol}$. After the minimization, acceptance was determined by the following criteria.

(1) Execution of a conformational search by the simulated annealing method with heat time $0.1 \mathrm{ps}$, run time $0.5 \mathrm{ps}$, cool time $0.1 \mathrm{ps}$, starting temperature $100 \mathrm{~K}$, simulation temperature $300 \mathrm{~K}$, and a temperature step $30 \mathrm{~K}$. which was described by Choe et al. [10].

(2) The structure obtained was minimized with a semiempirical method (PM3) and we verified that there were no negative frequencies in the vibration spectrum [10]. For the simulation and computational methods we adopted Hyperchem 8.0. All calculations refer to isolated molecules in vacuum. 


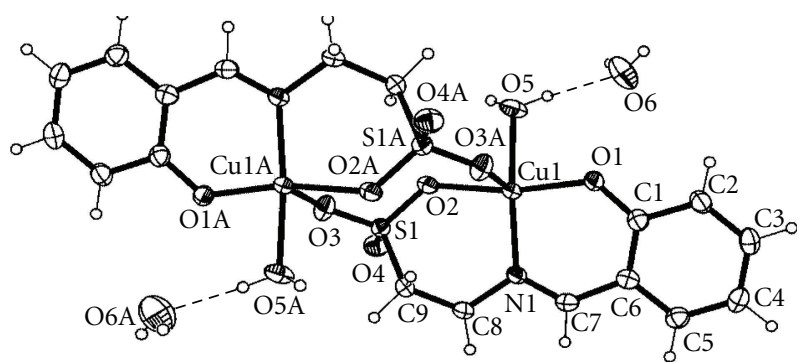

FIgure 5: Reprinted with permission crystal structure of $\left[\mathrm{Cu}_{2}(\text { Saes })_{2}\left(\mathrm{H}_{2} \mathrm{O}\right)_{2}\right] \cdot 2 \mathrm{H}_{2} \mathrm{O}(2)$.

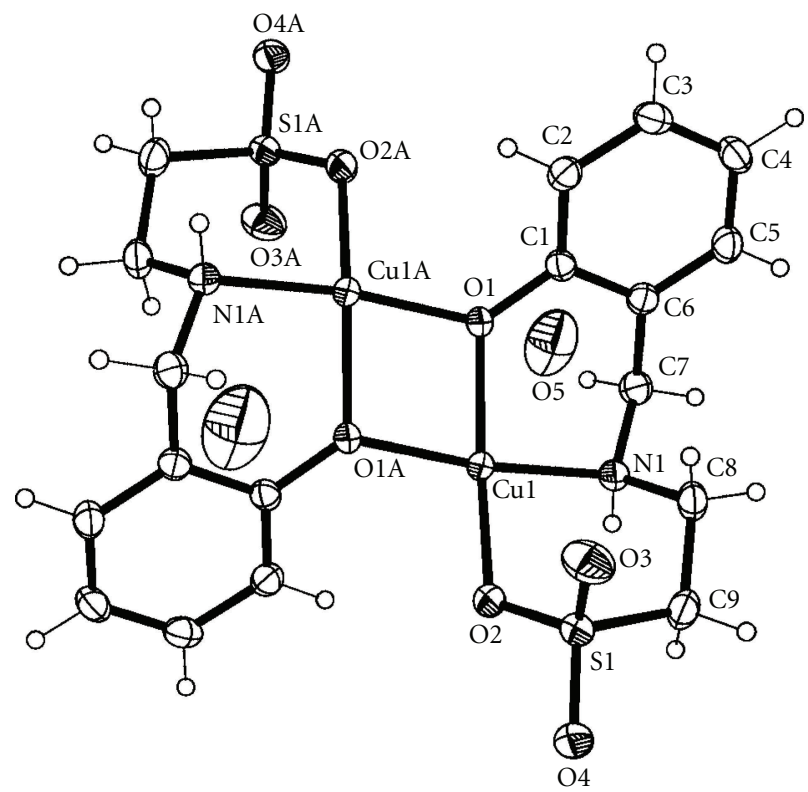

Figure 6: Reprinted with permission Crystal Structure of $\left[\mathrm{Cu}_{2}(\mathrm{Sae})_{2}\right] \cdot 2 \mathrm{H}_{2} \mathrm{O}$.

TABLe 3: Bond distances of complex $\left[\mathrm{Cu}_{2}(\mathrm{Saes})_{2}\left(\mathrm{H}_{2} \mathrm{O}\right)_{2}\right]$ unit in $\AA$.

\begin{tabular}{lcccc}
\hline & X-ray & MM+ & PM3 & DFT \\
\hline $\mathrm{Cu}(1)-\mathrm{N}(1)$ & 1.96 & 1.92 & 1.92 & 1.91 \\
$\mathrm{Cu}(1)-\mathrm{O}(5)$ & 1.98 & 1.98 & 1.98 & 2.18 \\
$\mathrm{Cu}(1)-\mathrm{O}(3) \mathrm{A}$ & 2.41 & 1.91 & 1.91 & 1.59 \\
$\mathrm{C}(7)-\mathrm{N}(1)$ & 1.28 & 1.31 & 1.27 & 1.30 \\
$\mathrm{~N}(1)-\mathrm{C}(8)$ & 1.47 & 1.48 & 1.32 & 1.49 \\
$\mathrm{O}(3)-\mathrm{Cu}(1) \mathrm{A}$ & 2.41 & 1.92 & 1.96 & 1.92 \\
$\mathrm{Cu}(1)-\mathrm{Cu}(1) \mathrm{A}$ & 5.33 & 4.42 & 3.5 & 3.12 \\
\hline
\end{tabular}

2.2. Semiempirical Optimization of Complexes. Semi empirical method is another tool for the determination of stability of molecule by incorporating quantum mechanical parameters into the calculation. We used PM3 method for the semi empirical calculation. The molecule constructed in the hyperchem GUI is initially optimized by using MM+ force field and Polak-Ribiere optimizer, then PM3 method

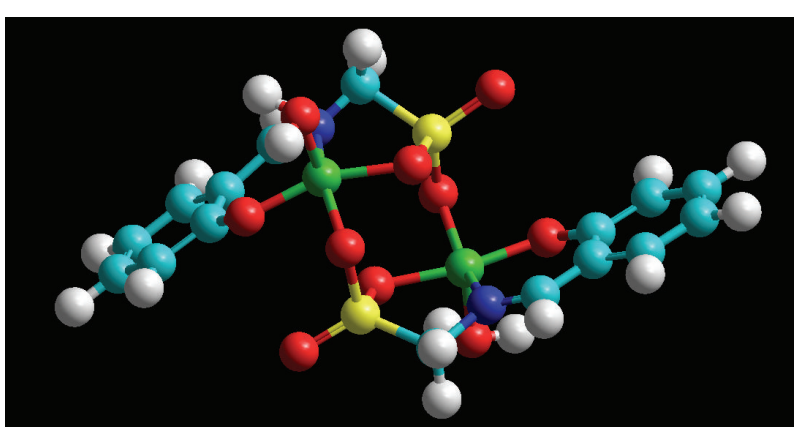

Figure 7: Computational structure of $\left[\mathrm{Cu}_{2}(\mathrm{Sams})_{2}\left(\mathrm{H}_{2} \mathrm{O}\right)_{2}\right]$.

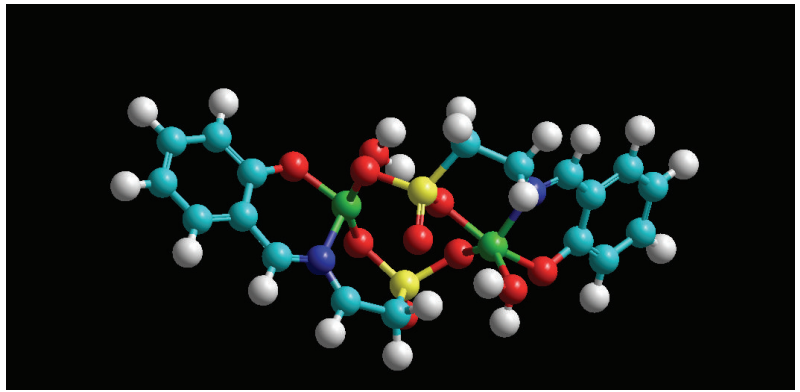

Figure 8: Computational structure of $\left[\mathrm{Cu}_{2}(\mathrm{Saes})_{2}\left(\mathrm{H}_{2} \mathrm{O}\right)_{2}\right]$.

TABLE 4: Bond angles of complex $\left[\mathrm{Cu}_{2}(\mathrm{Saes})_{2}\left(\mathrm{H}_{2} \mathrm{O}\right)_{2}\right]$ in degrees.

\begin{tabular}{lcccc}
\hline$\left[\mathrm{Cu}_{2}(\mathrm{Saes}) 2\left(\mathrm{H}_{2} \mathrm{O}\right)_{2}\right]$ & X-ray & $\mathrm{MM}+$ & PM3 & DFT \\
\hline $\mathrm{O}(1)-\mathrm{Cu}(1)-\mathrm{O}(2)$ & 168.87 & 176.80 & 171.77 & 158.00 \\
$\mathrm{~N}(1)-\mathrm{Cu}(1)-\mathrm{O}(5)$ & 166.9 & 142.60 & 110.77 & 124.00 \\
$\mathrm{O}(1)-\mathrm{Cu}(1)-\mathrm{N}(1)$ & 94.08 & 92.41 & 97.31 & 90.30 \\
$\mathrm{O}(2)-\mathrm{Cu}(1)-\mathrm{N}(1)$ & 97.04 & 85.86 & 90.24 & 96.04 \\
$\mathrm{O}(1)-\mathrm{Cu}(1)-\mathrm{O}(5)$ & 85.74 & 91.70 & 90.88 & 85.06 \\
$\mathrm{O}(2)-\mathrm{Cu}(1)-\mathrm{O}(5)$ & 83.56 & 94.80 & 89.43 & 107.00 \\
$\mathrm{O}(1)-\mathrm{Cu}(1)-\mathrm{O}(3)$ & 87.32 & 89.00 & 84.28 & 85.00 \\
$\mathrm{O}(2)-\mathrm{Cu}(1)-\mathrm{O}(3 \mathrm{~A}$ & 89.54 & 89.10 & 87.49 & 91.00 \\
$\mathrm{~N}(1)-\mathrm{Cu}(1)-\mathrm{O}(3) \mathrm{A}$ & 103.30 & 158.2 & 156.41 & 163.01 \\
$\mathrm{O}(5)-\mathrm{Cu}(1)-\mathrm{O}(3) \mathrm{A}$ & 89.70 & 88.3 & 92.68 & 88.68 \\
\hline
\end{tabular}

is applied on the molecule. As in MM+ calculations all the parameters refer to isolated molecules in vacuum.

2.3. Density Functional Analysis of the Complexes. Recently density functional-based methods have been applied to a wide range of chemical problems including coordination compounds. Most successful chemical applications of density functional theory have probably been in the field of organometallic chemistry. A widely used variant of the B3 hybrid functional is termed B3LYP [11]. The calculated bond lengths reported via B3LYP, BP86, and MP2 are in very good agreement with the experimental results [12]. Thus we used hybrid functional termed B3LYP for the DFT calculation.

The bond distance data and bond angle data obtained from semi empirical, molecular mechanics, and DFT were given in Tables 1, 2, 3, 4, 5 and 6. These were compared 


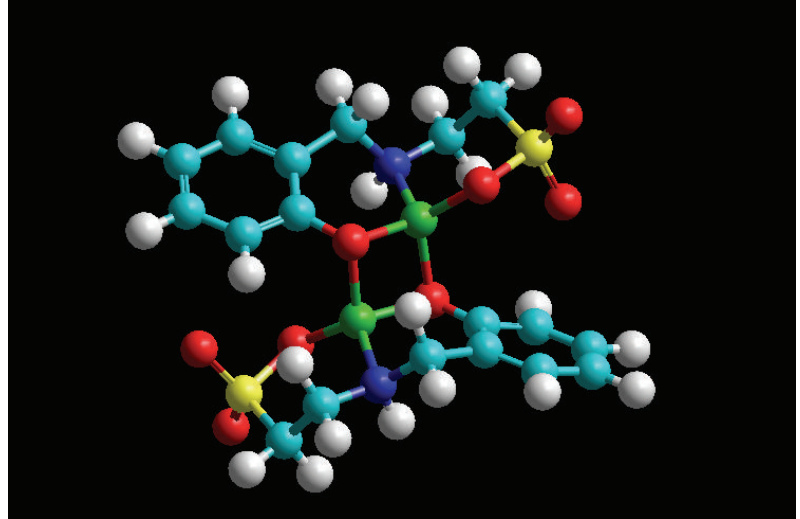

Figure 9: Computational structure of $\left[\mathrm{Cu}_{2}(\mathrm{Sae})_{2}\left(\mathrm{H}_{2} \mathrm{O}\right)_{2}\right]$.

TABle 5: Bond distances of complex $\left[\mathrm{Cu}_{2}(\mathrm{Sae})_{2}\right]$ unit in $\AA$.

\begin{tabular}{lcccc}
\hline & X-ray & MM+ & PM3 & DFT \\
\hline $\mathrm{Cu}(1)-\mathrm{O}(1) \mathrm{A}$ & 1.93 & 2.10 & 2.11 & 2.01 \\
$\mathrm{Cu}(1)-\mathrm{O}(1)$ & 1.97 & 1.85 & 1.86 & 1.89 \\
$\mathrm{Cu}(1)-\mathrm{N}(1)$ & 1.98 & 1.90 & 1.90 & 1.95 \\
$\mathrm{Cu}(1)-\mathrm{O}(2)$ & 2.00 & 1.87 & 1.87 & 1.89 \\
$\mathrm{O}(1)-\mathrm{Cu}(1) \mathrm{A}$ & 1.93 & 2.08 & 2.08 & 2.00 \\
$\mathrm{Cu}(1)-\mathrm{O}(1) \mathrm{A}$ & 1.93 & 2.10 & 2.11 & 1.98 \\
$\mathrm{C}(7)-\mathrm{N}(1)$ & 1.49 & 1.51 & 1.51 & 1.50 \\
$\mathrm{~N}(1)-\mathrm{C}(8)$ & 1.47 & 1.53 & 1.53 & 1.49 \\
$\mathrm{Cu}(1)-\mathrm{Cu}(1) \mathrm{A}$ & 3.03 & 2.22 & 2.21 & 2.11 \\
\hline
\end{tabular}

TABLE 6: Bond angles of complex $\left[\mathrm{Cu}_{2}(\mathrm{Sae})_{2}\right]$ in degrees.

\begin{tabular}{lcccc}
\hline & X-ray & MM+ & PM3 & DFT \\
\hline $\mathrm{S}(1)-\mathrm{O}(2)-\mathrm{Cu}(1)$ & 120.58 & 126.49 & 126.13 & 122.23 \\
$\mathrm{O}(1) \mathrm{a}-\mathrm{Cu}(1)-\mathrm{O}(1)$ & 78.09 & 87.83 & 87.83 & 81.83 \\
$\mathrm{O}(1) \mathrm{a}-\mathrm{Cu}(1)-\mathrm{N}(1)$ & 172.15 & 97.99 & 125.69 & 123.09 \\
$\mathrm{O}(1)-\mathrm{Cu}(1)-\mathrm{N}(1)$ & 94.31 & 97.99 & 97.99 & 98.96 \\
$\mathrm{O} 1) \mathrm{a}-\mathrm{Cu}(1)-\mathrm{O}(2)$ & 95.32 & 93.92 & 93.92 & 93.90 \\
$\mathrm{O}(1)-\mathrm{Cu}(1)-\mathrm{O}(2)$ & 152.72 & 164.24 & 164.24 & 164.04 \\
\hline
\end{tabular}

with the experimental data reported by Sreenivasulu et al. [3], and the comparative results were given in Tables 7 and 8. The structure of optimized molecule was represented in Figures 7-9. Majority of the parameter values were in close agreement with experimental values even though some discrepancy was observed. The reason for change in certain parameters can be attributed to computational chemistry methods. Most computational methods will determine minima on the PES, that is, nuclear positions at zero Kelvin, without consideration of harmonic vibrations. All experimental determinations will take place at higher temperature and thus will include contributions from thermal vibrations, in effect lengthening most bonds slightly [8]. Crystal packing can have a strong influence on torsions in particular but also on any long interatomic distances. Even then we noticed a big anomaly in the bond angle of $\mathrm{O}(5)-\mathrm{Cu}(1)-\mathrm{N}(1)$ bond angles
TABLE 7: Calculation of energy parameters by using molecular mechanics.

\begin{tabular}{|c|c|c|}
\hline & Ligand Sams & Complex \\
\hline Energy & 0.15 & 68.7 \\
\hline Bond & 0.64 & 4.94 \\
\hline Angle & 5.22 & 58.92 \\
\hline Dihedral & 8.41 & 7.3 \\
\hline Vdw & 7.38 & 19.42 \\
\hline Stretch-bend & 0.63 & 7.67 \\
\hline \multirow[t]{2}{*}{ Electrostatic } & -4.3 & 0.03 \\
\hline & Ligand Sae & Complex \\
\hline Energy & 1.96 & 55.3 \\
\hline Bond & 0.85 & 2.5 \\
\hline Angle & 5.7 & 50.61 \\
\hline Dihedral & 8.6 & 2.96 \\
\hline Vdw & 6.5 & 6.61 \\
\hline Stretch-bend & 0.73 & 1.98 \\
\hline \multirow[t]{2}{*}{ Electrostatic } & 5.85 & 0.32 \\
\hline & Ligand Saes & Complex \\
\hline Energy & -4.8 & 67.12 \\
\hline Bond & 0.73 & 4.9 \\
\hline Angle & 5.33 & 58.9 \\
\hline Dihedral & 7.55 & 8.55 \\
\hline Vdw & 5.59 & 19.6 \\
\hline Stretch-bend & 0.75 & -7.6 \\
\hline Electrostatic & 7.5 & 0.04 \\
\hline
\end{tabular}

Units $\mathrm{Kcal} / \mathrm{mol}$.

in all three complexes. We tried to explain these anomalies by considering the crystal packing effect. But we could not explain the particular discrepancy because this effect was present even when water molecules were absent. We modeled these three molecules with three layers and studied the hydrogen bond interaction effect but the variation in bond parameters was minimal. If the crystal packing effect was compressing the molecule, then that effect should not lie only on one bond distance $(\mathrm{O}(5)-\mathrm{Cu}(1)-\mathrm{N}(1))$. So we suggest a calibration of plane of that molecular plane section in $\mathrm{X}$ ray crystallographic studies.

2.4. Calculation of Energy Parameters by Using Molecular Mechanics and PM3 Simulations. Another interesting point we analyzed by using the molecular mechanics calculations was the prediction of the stability of this molecule by using $\mathrm{MM}+$ force field and PM3 calculation by hyperchem. The result obtained in this calculation was summarized in Tables 7 and 8. The computational structures of complex were represented in Figures 7, 8, and 9

2.5. PM3 IR Simulation. The proposed structures of the samples were optimized and their IR were spectra generated based on PM3 semiempirical calculations using Hyperchem 
TABLE 8: Calculation of energy parameters by using semi empirical methods (PM3) units Kcal/mol.

\begin{tabular}{lcccccc}
\hline & \multicolumn{2}{c}{ Sams } & \multicolumn{2}{c}{ Saes } & \multicolumn{2}{c}{ Sae } \\
& Ligand & Complex & Ligand & Complex & Ligand & Complex \\
\hline Total energy & -60163.86 & -188663.60 & -60889.50 & -195558.20 & -64338.70 & -181974.60 \\
Binding energy* & -2374.54 & -5323.99 & -2497.23 & -5882.57 & -2778.40 & -5644.11 \\
Heat of formation & -120.87 & -536.13 & -139.35 & -544.51 & -145.43 & -425.18 \\
\hline
\end{tabular}

* Binding energy is the energy required to release an electron from its atomic or molecular orbital.

molecular modeling software. The assignment of the calculated wave numbers was aided by the animation option of same program, which gave a visual presentation of the shape of the vibrational modes.

Infrared spectra of ligand and their complexes have been analyzed by FT IR by Sreenivasulu et al. [3]. This experimental data was compared with computational values obtained by PM3 method and subsequent force matrix generation. We gave assignment of the most important infrared bands of the complex samples with the aim of detecting the coordination effects. The molecules have some possible donor sites. According to the experimental study complexes show absorption bands at 3400, 3443, and $3410 \mathrm{~cm}^{-1}$ corresponding to the presence of water molecules ${ }^{10}$. In PM3 simulation also peak for the water molecule was 3450 to 3550 . The $\mathrm{C}=\mathrm{N}$ stretching frequencies were observed at $1629 \mathrm{~cm}^{-1}$ in 1 and $1617 \mathrm{~cm}^{-1} 2$. The PM3 value was also in the same range $(1620-1675) \mathrm{cm}^{-1}$. As the $\mathrm{C}=\mathrm{N}$ bond was reduced in 3 the $\mathrm{N}-\mathrm{H}$ stretching frequencies appeared in the range of $2920-2935 \mathrm{~cm}^{-1}$ [3]. The PM3 value in this case is $3325 \mathrm{~cm}^{-1}$. The frequencies characteristics of the $\mathrm{S}-\mathrm{O}$ stretching modes were observed in the range 1000 $1380 \mathrm{~cm}^{-1}$. These values were also in good correlation with PM3 studies

\section{Conclusion}

The molecular mechanics $(\mathrm{MM}+)$ method and semiempirical PM3 and density functional method were used to calculate bond distance, bond angle, and infrared spectra of the titled compounds. It was found that some of the bond lengths and bond angles were in agreement with $\mathrm{X}$ ray crystallographic method. But some discrepancy was occurring in $\mathrm{Cu}-\mathrm{O}$ bond length and $\mathrm{Cu}-\mathrm{Cu}$ bond lengths. We noticed a big anomaly in the bond angle of $\mathrm{O}(5)$ $\mathrm{Cu}(1)-\mathrm{N}(1)$ bond angles in all three complexes. But the one discrepancy observed in all three complexes was suggesting the recalibration of X ray crystallographic data. It was found that the simulated IR spectra were in consistence with the experimental data.

\section{Acknowledgments}

The authors thank Head of the Department of Chemistry, University of Calicut, Malabar Christian College Calicut and also the University Grants Commission, New Delhi, for financial assistance. They are thankful to Wiley and Professor
Sreenivasaulu for permitting the publication of figures and crystallographic data.

\section{References}

[1] E. R. Davidson, "Quantum theory of matter: introduction," Chemical Reviews, vol. 91, p. 649, 1991.

[2] P.-O. Norrby, "Recipe for an organometallic force field," in Computational Organometallic Chemistry, T. Cundari, Ed., Marcel Dekker, New York, NY, USA, 2001.

[3] B. Sreenivasulu, M. Vetrichelvan, F. Zhao, S. Gao, and J. J. Vittal, "Copper(II) complexes of schiff-base and reduced schiff-base ligands influence of weakly coordinating sulfonate groups on the structure and oxidation of 3,5-DTBC," European Journal of Inorganic Chemistry, no. 22, pp. 4635-4645, 2005.

[4] K. Tatsumoto and A. E. Martell, "Pyridoxal- and metalcatalyzed $\beta$-elimination, decarboxylation, and dealdolation reactions of $\beta$-hydroxyglutamic acid," Journal of the American Chemical Society, vol. 103, no. 20, pp. 6203-6208, 1981.

[5] K. Tatsumoto, A. E. Martell, and R. J. Motekaitis, "Reaction kinetics and equilibria of $\beta$-elimination of some schiff base complexes," Journal of the American Chemical Society, vol. 103, no. 20, pp. 6197-6203, 1981.

[6] H. M. Dawes, J. M. Waters, and T. N. Waters, "Some observations on the structures of pyridoxal-aminoacid schiff base complexes," Inorganica Chimica Acta, vol. 66, pp. 29-36, 1982.

[7] I. Bkouche-Waksman, J. M. Barbe, and Å. Kvick, "A model for vitamin $\mathrm{B}_{6}$-amino-acid-related metal complexes. Neutron diffraction study of aqua( $N$-salicylideneglycinato) $\operatorname{copper(II)}$ hemihydrate at $130 \mathrm{~K}, "$ Acta crystallographica Section B, vol. 44, pp. 595-601, 1988.

[8] R. Hamalainen, U. Turpeinen, and Å. Kvick, "Crystal Structure Communications," Acta crystallographica Section C, vol. 41, pp. 1726-1728, 1985.

[9] "Hyperchem 8 evaluation, hyperchem," (student licence), http://www.hyperchem.com/.

[10] J.-I. Choe, K. Kim, and S.-K. Chang, "Molecular modeling of complexation of alkyl ammonium ions by p-tertbutylcalix[4]crown-6-ether," Bulletin of the Korean Chemical Society, vol. 21, no. 5, pp. 465-470, 2000.

[11] P. J. Stephens, F. J. Devlin, C. F. Chabalowski, and M. J. Frisch, "Ab Initio calculation of vibrational absorption and circular dichroism spectra using density functional force fields," Journal of Physical Chemistry, vol. 98, no. 45, pp. 11623-11627, 1994.

[12] T. Wagener, G. Franking, et al., "The accuracy of quantum chemical methods for the calculation of transition metal compounds michael diedenhofen," in Computational Organometallic Chemistry, T. Cundari, Ed., p. 72, Marcel Dekker, New York, NY, USA, 2001. 


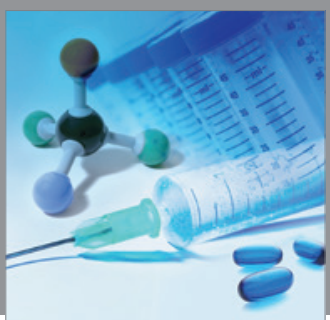

International Journal of

Medicinal Chemistry

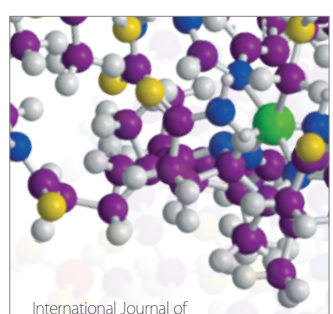

Carbohydrate Chemistry

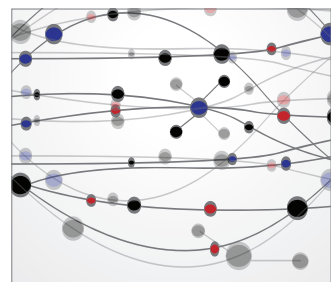

The Scientific World Journal
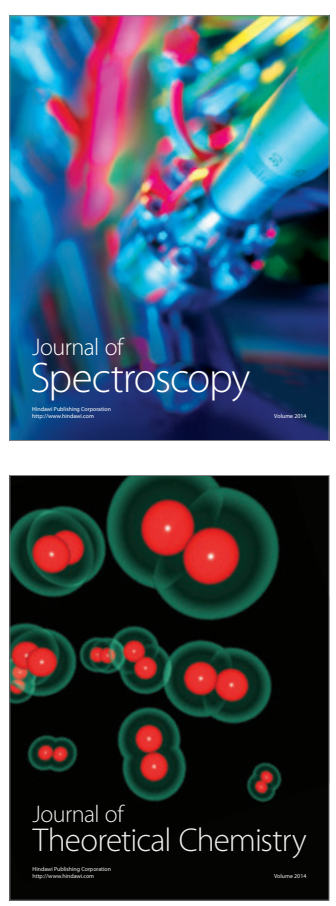
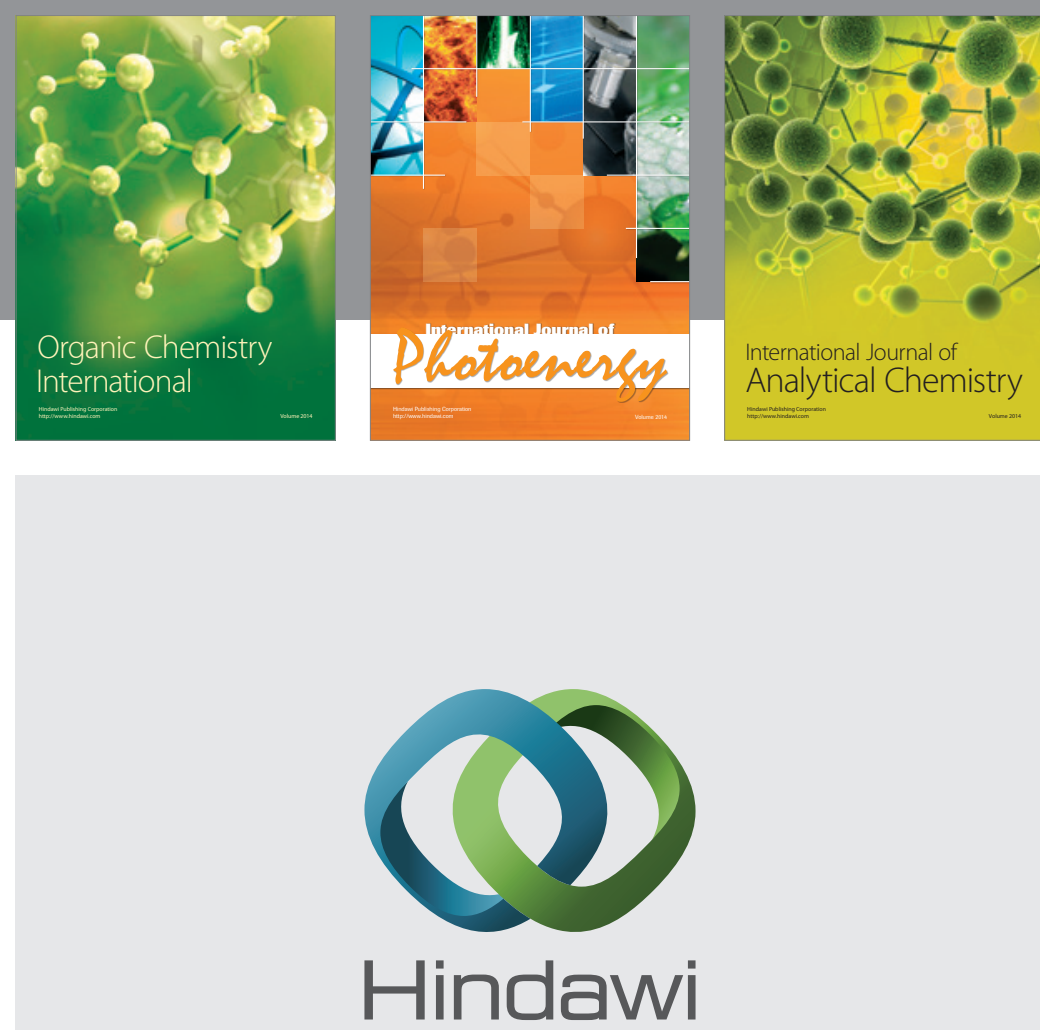

Submit your manuscripts at

http://www.hindawi.com
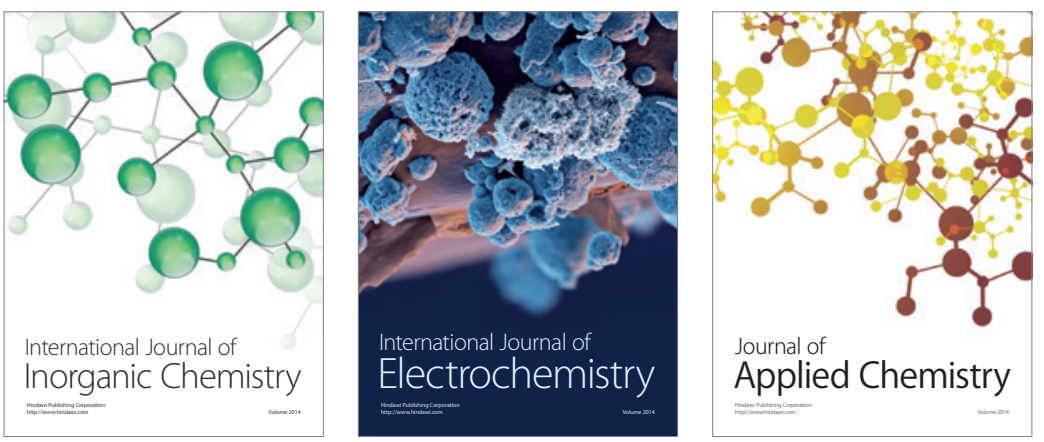

Journal of

Applied Chemistry
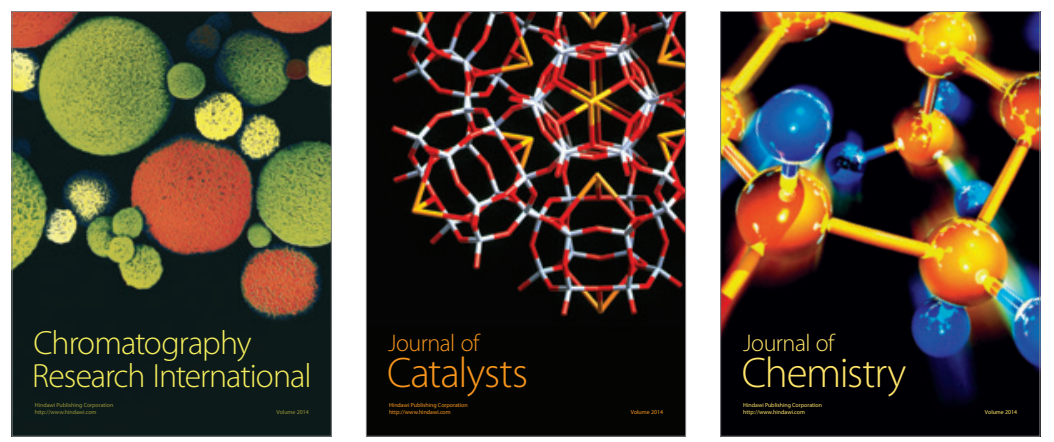
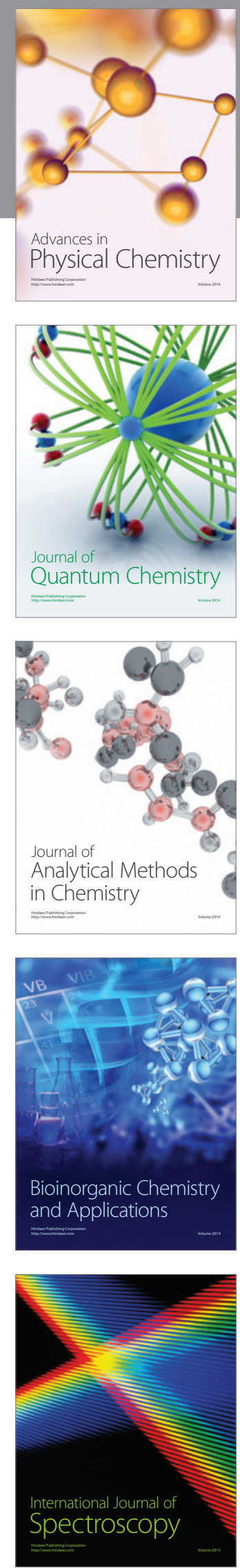